Article

\title{
Combined Effect of Spirulina Platensis and Punica Granatum Peel Extacts: Phytochemical Content and Antiphytophatogenic Activity
}

\author{
Hajer Ben Hlima ${ }^{1, *}$, Thouraya Bohli ${ }^{2,3}$, Mariem Kraiem ${ }^{1,2}$, Abdelmottaleb Ouederni ${ }^{3}$, \\ Lotfi Mellouli $^{4}$, Philippe Michaud ${ }^{5}$ (D), Slim Abdelkafi ${ }^{1}$ (D) and Slim Smaoui ${ }^{4}$ (D) \\ 1 Unité de Biotechnologie des Algues, Biological Engineering Department, National School of Engineers of \\ Sfax, University of Sfax, Sfax 3018, Tunisia; Mariem.Kraiem1@gmail.com (M.K.); \\ slim.abdelkafi@enis.tn (S.A.) \\ 2 Farm of Spirulina Culture, 37, Cité SNIT-Mtorrech, Gabes 6036, Tunisia; thouraya.bohli@gmail.com \\ 3 Laboratory of Research, Process Engineering and Industrial Systems (LR11ES54), National School of \\ Engineers of Gabes, University of Gabes, Gabes 6026, Tunisia; Abdelmottaleb.Ouederni59@gmail.com \\ 4 Laboratoire de Microorganismes et de Biomolécules du Centre de Biotechnology de Sfax, Route Sidi \\ Mansour Km 6 B.P. 117, Sfax 3018, Tunisia; lotfi.mallouli@cbs.rnrt.tn (L.M.); slim.smaoui@yahoo.fr (S.S.) \\ 5 Université Clermont Auvergne, CNRS, SIGMA Clermont, Institut Pascal, F-63000 Clermont-Ferrand, France; \\ philippe.michaud@uca.fr \\ * Correspondence: hajer.benhlima@enis.tn
}

Received: 16 October 2019; Accepted: 8 December 2019; Published: 13 December 2019

Abstract: Biological control is one of the effective methods for managing plant diseases in food production and quality. In fact, there is a growing trend to find new bio-sources, such as marine algae and vegetal by-products. In this study, pomegranate (Punica granatum) peel (S1) and Spirulina platensis (S2) alone and in combinations, pomegranate peel/Spirulina: $25 \% / 75 \%$ (S3) and 50\%/50\% (S4) were evaluated for antimycotoxigenic and antiphytopathogenic fungal properties. The chemical composition (moisture, dry matter, protein, lipid and ash) as well as total polyphenols, flavonoids and anthocyanins content were evaluated in the four extracts. Using agar diffusion and broth microdilution methods, the anti Fusarium oxysporum, Fusarium culmorum, Fusarium graminearum, Aspergillus niger and Alternaria alternata activities were measured and their correlations with phytochemical content were evaluated. Interestingly, combinations between Spirulina at $75 \%$ and pomegranate peel at $25 \%$ (S3) have a significant impact $(p<0.05)$ on the antifungal activity compared to S1, S2 and S4. These findings underlie the effectiveness of biocontrols over standard fungicides and imply that existing methods can be further improved by synergistic effects while maintaining food safety in an eco-friendly manner.

Keywords: Spirulina; pomegranate peel; antifungal activity; chemical composition; phytochemical content; antimycotoxigenic; antiphytopathogenic

\section{Introduction}

Due to the occurrence of fungal resistance to synthetic fungicides, the use of chemical compounds is strictly controlled and their application is subjected to tighter regulations [1,2]. Therefore, the use of biological substances with antimicrobial properties redirected researchers for the development of novel and stable approaches that are less inducible to antimicrobial resistance in order to replace chemical fungicides, bactericides and pesticides for food preservation and safety as well as plant crop protection. Furthermore, the growing interest in biological food additives has challenged the scientific community to innovate in alternative food preservation and plant crop protection systems. Thus, 
natural preservatives from sources like bacteria, plants and algae were reported to ensure food safety due to their antimicrobial activity against a wide spectrum of foodborne pathogens [3,4]. In this regard, dietary antioxidants (i.e., phenolic compounds) have recently attracted extensive attention because of their ubiquity in nature and their various beneficial effects, including antimicrobial, antioxidant, antiinflammatory and antiproliferative activities [5].

One of the readily available sources of such compounds is by-products from the agro-food industry. For example, pomegranate processing generates a large amount of solid wastes. In fact, per $1000 \mathrm{~g}$ of raw pomegranate fruit, the edible portion accounts for only half ( $400 \mathrm{~g}$ of juice and $100 \mathrm{~g}$ of seeds) and the rest, almost $500 \mathrm{~g}$ (e.g., peels), is discarded as waste [6]. Pomegranate peel has remarkable antioxidant and antimicrobial properties. Rich in flavonoids, phenolic acids and tannins, pomegranate peels are known to possess important and diverse biological and pharmacological properties $[7,8]$. Šavikin et al. reported that pomegranate peel exhibits high levels of free radical scavenging activities and strong antimicrobial activity due to its phenolic content [9]. Several studies reported the efficacy of extracts from pomegranate peel to inhibit both Gram-positive and Gram-negative bacterial growth such as foodborne pathogens, spoilage bacteria and human pathogens [10]. It was reported as well that pomegranate extracts display antifungal properties [11]. In fact, some extracts have anti Candida sp. and anti Saccharomyces cervisiae activities [12] and, more recently, both peel powder and extracts were demonstrated to inhibit the growth of Penicillium spp., two mycotoxigenic Aspergilli strains (A. flavus and A. ochraceus) [13], two Colletotricum strains as well as Rhizopus stolonifer, Botrytis cinerea, and Rhizoctonia solani strains [14,15]. Some studies reported that the proportion of carbohydrate in pomegranate peel was about $15 \%$ and that the polysaccharides extracted from pomegranate had obvious biological functions [16].

Spirulina (Arthrospira platensis), a microscopic and filamentous cyanobacterium, has been recently recommended as a sustainable, highly nutritional and ecofriendly microalga [17]. Spirulina contains potent antioxidants, free-radical scavengers [18] and is able to inhibit the growth of some Gram-negative, Gram-positive bacteria and yeast such as Candida albicans [18]. Polysaccharides extracted from Spirulina have antitumor, antioxidation, antiaging, and antivirus properties [19]. Nevertheless, little information about antifungal properties, especially against mycotoxigenic and phytopathogenic fungi, of Spirulina platensis is available in the literature and its potential toxic effects have not been largely investigated.

To date, there is no study that has addressed mycotoxigenic and phytopathogenic properties when pomegranate and Spirulina were combined. Therefore, the objective of this research was to evaluate the composition of Spirulina alone and in combination with pomegranate peel extracts and to study their potential on the antifungal activity. Associations between phytochemical content and antifungal properties were discussed based on Pearson coefficients.

\section{Materials and Methods}

\subsection{Algal Culture and Growth Conditions}

Spirulina platensis was provided by Eden Life Aquaculture-Company (Gabes, Tunisia). Under photoautotrophic conditions, the culture was performed with Zarrouk medium containing $\mathrm{NaHCO}_{3}$ (PubChem CID: 516892) 16.8 g; $\mathrm{K}_{2} \mathrm{HPO}_{4}$ (PubChem CID: 24450) 0.5 g; $\mathrm{NaNO}_{3}$ (PubChem CID: 24268) 2.5 g; NaCl (PubChem CID: 5234) 1.0 g; $\mathrm{MgSO}_{4}$. 7 $\mathrm{H}_{2} \mathrm{O}$ (PubChem CID: 24843) 0.2 g; $\mathrm{FeSO}_{4} .7 \mathrm{H}_{2} \mathrm{O}$ (PubChem CID: 24393) $0.01 \mathrm{~g} ; \mathrm{K}_{2} \mathrm{SO}_{4}$ (PubChem CID: 24507) $1.0 \mathrm{~g} ; \mathrm{CaCl}_{2} .2 \mathrm{H}_{2} \mathrm{O}$ (PubChem CID: 5284359) $0.04 \mathrm{~g}$ and EDTA (PubChem CID: 6049) $0.08 \mathrm{~g}$ for 1 litre of medium [20]. Zarrouk's nutrient medium was purchased from Scharlau (Barcelona, Spain). The initial $\mathrm{pH}$ was adjusted to 9.5, and was found to increase only slightly during cultivation. The culture was illuminated at a light intensity of $80 \mathrm{mEm}^{-2} \mathrm{~s}^{-1}$. The culture temperature was maintained at $30 \pm 0.1^{\circ} \mathrm{C}$, while the culture was agitated at $300 \mathrm{rpm}$. S. platensis was grown for $108 \mathrm{~h}$ until the late exponential phase when cells were collected and freeze-dried. 


\subsection{Preparation of Ethanolic Extract of Spirulina platensis (S. platensis)}

Ethanolic extract was prepared by stirring $100 \mathrm{~g}$ of freeze-dried S. platensis with $300 \mathrm{~mL}$ of ethanol (PubChem CID: 702) (Novachim, Bucharest, Romania) for $24 \mathrm{~h}$ at $40^{\circ} \mathrm{C}$ in the dark. After filtration, the obtained extract was concentrated in a rotary evaporator (Laborota 4000, Heidolph, Milan, Italy), then dried in a lyophilizer (Martin Christ, Alpha 1-2 LD plus Germany). The resulting extract of S. platensis from ethanol was kept at $+4{ }^{\circ} \mathrm{C}$ until use.

\subsection{Plant Material and Extraction}

Fruits of the pomegranate (Punica granatum L. Tunisian cultivar 'Gabsi') were obtained from a commercial harvest on local farms in Gabes $\left(\mathrm{N}: 33.53^{\circ}, \mathrm{E}: 10.07^{\circ}\right)$. Peels were washed with running water, air-dried at room temperature, then powdered with an electric grinder (The original grinder, Moulinex, France) to the diameter of $0.5 \mathrm{~mm}$. One hundred grams of powdered peels were soaked in ethanol at room temperature for $24 \mathrm{~h}$ in the dark. The extraction mixture was well decanted and filtered, then evaporated at $40{ }^{\circ} \mathrm{C}$ and lyophilized to obtain a yellow-brown residue which was immediately analyzed.

\subsection{Extracts Preparation}

The combination between pomegranate peel and Spirulina was assessed in order to detect the maximum synergistic effect between the two ethanolic extracts. Four samples: S1, S2, S3 and S4 representing the mixture design of its binary combinations: S1 (pomegranate peel), S2 (Spirulina), S3 (pomegranate peel—Spirulina: 25\%/75\%) and S4 (pomegranate peel—Spirulina: 50\%/50\%) were studied.

\subsection{Physico-Chemical Analysis}

\subsubsection{Dry Matter}

The dry matter was ascertained according to the Association of Official Analytical Chemists: samples were dried at $105 \pm 3{ }^{\circ} \mathrm{C}$ to constant weights [21,22].

\subsubsection{Protein Content}

The total protein content was determined by the Kjeldahl method. The protein content was calculated by using a nitrogen conversion factor of 6.25 and expressed as percent of dry weight [22].

\subsubsection{Fat Content}

Lipids were extracted by using the protocol described in the standard NF V 03-713 [23]. Eight grams of each sample were hydrolyzed with a mixture of ethanol, formic acid (PubChem CID: 284) (Sigma, Taufkirchen, Germany) and 70\% hydrochloric acid (PubChem CID: 313) (Sigma, Taufkirchen, Germany) for $20 \mathrm{~min}$ at $75^{\circ} \mathrm{C}$. Chloroform (PubChem CID: 6212) (Novachim, Bucharest, Romania) was then used as solvent for oil extraction and the samples were cooled under agitation. Sixteen milliliters of ethanol and $50 \mathrm{~mL}$ of chloroform were added and the mixtures obtained were agitated for $20 \mathrm{~min}$. The extracting procedure was repeated twice. The collected solvent was then removed by means of rotary evaporator at $50{ }^{\circ} \mathrm{C}$. These data were expressed as percentage of lipids per sample dry matter.

\subsubsection{Ash Content}

To remove carbon, each sample was ignited and incinerated in a muffle furnace at a temperature of $550{ }^{\circ} \mathrm{C}$ for $16 \mathrm{~h}$ [24]. 


\subsection{Quantitative Determination of Phenolic Compounds}

\subsubsection{Total Polyphenols Content (TPC)}

Total polyphenols content (TPC) of each sample was determined by the Folin-Ciocalteu method [25]. For each diluted extract, 10 microliters were mixed with $50 \mu \mathrm{L}$ of Folin-Ciocalteau reagent (Sigma-Aldrich GmbH, Steinheim, Germany) and shaken for $5 \mathrm{~min}$. Then $150 \mu \mathrm{L}$ of $20 \% \mathrm{Na}_{2} \mathrm{CO}_{3}$ (PubChem CID: 10340) (Scharlau, Barcelona, Spain) was added and the mixture was shaken once again for $1 \mathrm{~min}$. Finally, the solution was set to $790 \mu \mathrm{L}$ by adding distilled water. After two hours, the absorbance at $760 \mathrm{~nm}$ was measured using a spectrophotometer (Bibby Scientific Limited, Stone, UK). The standard for the calibration curve was the Gallic acid (PubChem CID: 370) (Sigma-Aldrich GmbH, Steinheim, Germany) and finally TPC was expressed as $\mathrm{mg}$ of Gallic acid equivalent per $\mathrm{g}$ of sample (mg GAE/g) using the linear equation of the calibration curve.

\subsubsection{Total Flavonoids Content (TFC)}

Total flavonoids content (TFC) of each sample was determined using the method of Quettier-Deleu et al. [26]. One milliliter of $\mathrm{AlCl}_{3}$ (PubChem CID: 24012) (Scharlau, Barcelona, Spain) was added to $1 \mathrm{~mL}$ of each diluted extract solution, vortexed and incubated for $15 \mathrm{~min}$ in the dark. The absorbance was evaluated at $430 \mathrm{~nm}$ and the quercetin (PubChem CID: 5280343) (Sigma-Aldrich $\mathrm{GmbH}$, Steinheim, Germany) was used as standard for the calibration curve. TFC was expressed in $\mathrm{mg}$ of quercetin equivalent per $\mathrm{g}$ of extract $(\mathrm{mg} \mathrm{QE} / \mathrm{g})$.

\subsubsection{Total Tannins Content (TAC)}

Total tannins content (TAC) was evaluated by the $\mathrm{pH}$ differential technique using 2 buffer systems: potassium chloride buffer pH1.0, 0.025 M (PubChem CID: 4873) (Sigma-Aldrich GmbH, Steinheim, Germany) and sodium acetate buffer 4.5, 0.4 M (PubChem CID: 517045) (Loba Chemie Pvt. Ltd., Mumbai, India) $\mathrm{pH}$ ). Each extract was mixed with the corresponding buffer and read against water as blank in the two wavelength 510 and $700 \mathrm{~nm}$ [27]. Total tannins content was expressed as $\mathrm{mg}$ of cyanidin-3-glucoside equivalents (PubChem CID: 197081) (CGE) per $100 \mathrm{~g}$ of extract and was calculated from the following equation:

$$
\mathrm{TAC}=[(\mathrm{A} 510-\mathrm{A} 700) \mathrm{pH} 1.0-(\mathrm{A} 510-\mathrm{A} 700) \mathrm{pH} 4.5 \times \mathrm{MW} \times 1000] / \varepsilon
$$

where, $\mathrm{A}$ is absorbance value, $\mathrm{M}$ is molecular weight $(449.2 \mathrm{~g} / \mathrm{mol})$, DF is dilution factor and $\sum$ is the molar absorptivity of cyanidin3-glucoside $(26,900 \mathrm{~L} / \mathrm{mol} \mathrm{cm})$.

\subsection{Antimicrobial Activities}

\subsubsection{Antifungal Assays}

The antifungal activity of each extract was tested against Fusarium oxysporum CTM10402, Aspergillus niger CTM 10099, Fusarium graminearum ISPaVe 271, Fusarium culmorum ISPaVe 21w and Alternaria alternata CTM 10230. Fusarium oxysporum, Aspergillus niger and Alternaria alternata were provided by the local culture Collection of Tunisian Microorganisms (CTM) of the Centre of Biotechnology of Sfax (CBS Sfax-Tunisia). Fusarium graminearum ISPaVe 271, Fusarium culmorum ISPaVe 21w were provided by National School of Engineers of Sfax (ENIS Sfax-Tunisia). Fungal strains were maintained on potato dextrose agar (PDA) (Oxoid, Basingstoke, UK) medium and preserved at $4{ }^{\circ} \mathrm{C}$. All fungal strains were conserved in $50 \%$ glycerol (PubChem CID: 753) and $50 \%$ potato dextrose broth $(v / v)$ at $-20^{\circ} \mathrm{C}$.

For spore preparation, the fungal strains were grown in PDA medium for 7 days at $25^{\circ} \mathrm{C}$. Sterile distilled water was added to the agar plate surface and spores were liberated from fungal mycelium by scraping with a sterile glass spreader. The liquid mixture was collected and filtered through Miracloth (Calbiochem, Darmstadt, Germany) before a centrifugation at $4000 \mathrm{rpm}$ for $10 \mathrm{~min}$. The spore pellet 
was washed twice with sterile distilled water and resuspended in sterile distilled water again to obtain a final spore suspension. Fungal spore concentration was quantified under microscopy. The spore suspension obtained was adjusted to the concentration of $10^{4} \mathrm{spores} / \mathrm{mL}$. Spore suspension was directly used after preparation. Antifungal activity was determined by the agar diffusion test $[28,29]$. The quantity used for each extract was $50 \mu \mathrm{L}$ per disk (at $5 \mathrm{mg} / \mathrm{mL}$ ), and the plates were incubated at $30{ }^{\circ} \mathrm{C}$ for $72 \mathrm{~h}$ [28]. Dimethyl Sulfoxyde (DMSO) was used as a negative control, while Amphotericin $\mathrm{B}(20 \mu \mathrm{g} /$ wells $)$ was used as a positive control. Antifungal activity was evaluated by measuring the diameter $(\mathrm{mm})$ of circular inhibition zones around the well. Tests were performed in triplicate.

\subsubsection{Determination of Minimal Inhibitory Concentration (MIC) and the Minimal Fungicidal} Concentration (MFC)

For minimal inhibitory concentration (MIC) determination, each extract was dissolved in a solution of dimethylsulfoxide DMSO (PubChem CID: 679) (Loba Chemie Pvt. Ltd., Mumbai, India)/water (1/9; $v / v)$ to a final concentration of $0.078125,0.15625,0.3125,0.625,1.25,2.5,5,10$ and $20 \mathrm{mg} / \mathrm{mL}$ and then filtered through $0.22 \mu \mathrm{m}$ pore-size black polycarbonate filters (Millipore). The test was performed in sterile 96-well microplates using $100 \mu \mathrm{L}$ as a final volume for each well which contain $10 \mu \mathrm{L}$ of cell suspension corresponding to a final concentration of $10^{6} \mathrm{CFU} / \mathrm{mL}$ [30]. Positive growth control well consisted of fungi in Mueller Hinton broth (Oxoid, Basingstoke, UK) and DMSO/water (1/9) was used as negative control. The plates were then covered and incubated in appropriate temperature for $24 \mathrm{~h}$. The MIC was defined as the lowest concentration in which the microorganism did not demonstrate visible growth. As an indicator of fungal growth, $25 \mu \mathrm{L}$ of thiazolyl blue tetrazolium bromide (MTT) (PubChem CID: 64965) (Sigma-Aldrich, Taufkirchen, Germany) was added at $0.5 \mathrm{mg} / \mathrm{mL}$ to the well microplates and kept for $30 \mathrm{~min}$ at $37^{\circ} \mathrm{C}$. The tetrazolium salt was a colourless electron acceptor molecule which was reduced to a red-coloured formazan product with the growth of the indicator microorganisms. This salt would remain uncoloured if the microbial growth was blocked. MIC values were determined in triplicate.

Minimal fungicidal concentrations (MFCs) were determined by serial sub cultivation of $10 \mu \mathrm{L}$ in PDA plates and incubated for $72 \mathrm{~h}$ at $28^{\circ} \mathrm{C}$. The lowest concentration with no visible growth was defined as the MFC, indicating $\geq 99.9 \%$ killing of the original inoculum. The determinations of MIC and MFC values were done in triplicate. Extracts were then considered as fungistatic or fungicidal depending on the MFC/MIC ratios which were respectively greater or lesser than 4 [31].

\subsubsection{Statistical Analysis}

Computations were performed using the Statistical Package for the Social Sciences (SPSS) software (version 19.0; SPSS Inc., Chicago, IL, USA). The data was expressed as means \pm standard deviations of three replicates. Analysis of variance was done using Tukey's post-hoc test to determine the differences among means obtained for different samples. The level of significance was set to $p<0.05$ and Pearson correlation coefficients were generated to describe the relationship between phytochemical contents (TPC, TFC and TAC) and anti-fungal activity which was evaluated by measuring the inhibition zone $(\mathrm{mm})$

\section{Results and Discussion}

\subsection{Physicochemical Composition}

Physicochemical composition of Spirulina and its combinations with pomegranate peel (S1-S4) is shown in Table 1 Moisture content of ethanolic extracts was measured as a percentage of water relative to dry weight. Moisture content of pomegranate peel from 'Gabsi' cultivar used in this study (S1) was about $74.25 \pm 0.52 \%$ which is slightly higher than those found in other Tunisian cultivars: 'Acide', 'Nebli' and 'Tounsi', whose contents were respectively $67.26 \% ; 72.58 \%$ and $72.68 \%$ [32]. As illustrated in Table 1, moisture content of sample S2 (Spirulina) was $8.25 \pm 0.07 \%$. This value was higher 
than Hawaiien Spirulina Pacifica (4.70\%) and Algerian Spirulina (5.17\%) but lower than the Spirulina moisture content from Chad (8.40\%) [33]. In this study, moisture content was less than $10 \%$, which is the recommended condition for long-term storage of Spirulina powders. On the other hand, the combination S4 showed a significant difference $(p<0.05)$ compared to $\mathrm{S} 2$ for moisture content values.

Table 1. Physicochemical composition (moisture (\%), dry matter (\%), protein (\%), lipid (\%) and ash (\%)) and phytochemical content total polyphenols content: TPC (mg GAE/g), total flavonoids content: TFC (mg QE/g)) and total anthocyanins content: TAC (mg cy-3-glu/100 g) of the extracts from Spirulina platensis and its combinations with pomegranate peel.

\begin{tabular}{cccccc}
\hline & & S1 & S2 & S3 & S4 \\
\hline & Moisture & $74.25 \pm 0.52^{\mathrm{c}}$ & $8.25 \pm 0.07^{\mathrm{a}}$ & $11.85 \pm 0.13^{\mathrm{a}}$ & $41.35 \pm 0.47^{\mathrm{b}}$ \\
Chemical & Dry matter & $97.51 \pm 4.55^{\mathrm{c}}$ & $94.75 \pm 3.77^{\mathrm{b}}$ & $93.63 \pm 3.33^{\mathrm{ab}}$ & $92.65 \pm 2.52^{\mathrm{a}}$ \\
Properties & Protein & $7.68 \pm 0.22^{\mathrm{a}}$ & $69.54 \pm 3.44^{\mathrm{d}}$ & $54.52 \pm 3.01^{\mathrm{c}}$ & $37.42 \pm 2.68^{\mathrm{b}}$ \\
& Lipid & Nd & $7.18 \pm 0.42^{\mathrm{c}}$ & $5.15 \pm 0.28^{\mathrm{b}}$ & $2.75 \pm 0.19^{\mathrm{a}}$ \\
& Ash & $5.02 \pm 0.51^{\mathrm{a}}$ & $10.69 \pm 0.32^{\mathrm{c}}$ & $8.07 \pm 0.49^{\mathrm{b}}$ & $7.54 \pm 0.23^{\mathrm{b}}$ \\
\hline \multirow{2}{*}{ Phytochemical } & TPC & $131.14 \pm 5.25^{\mathrm{d}}$ & $4.59 \pm 0.21^{\mathrm{a}}$ & $34.5 \pm 1.72^{\mathrm{b}}$ & $66.75 \pm 3.25^{\mathrm{c}}$ \\
Content & TFC & $6.75 \pm 0.25^{\mathrm{d}}$ & $2.75 \pm 0.05^{\mathrm{a}}$ & $3.41 \pm 0.12^{\mathrm{c}}$ & $4.27 \pm 0.18^{\mathrm{b}}$ \\
& TAC & $24.51 \pm 1.15^{\mathrm{d}}$ & $0.51 \pm 0.01^{\mathrm{a}}$ & $5.87 \pm 0.05^{\mathrm{b}}$ & $12.02^{\mathrm{b}} \pm 0.65^{\mathrm{c}}$ \\
\hline
\end{tabular}

S1 (pomegranate peel), S2 (Spirulina), S3 (pomegranate peel—Spirulina: 25/75\%) and S4 (pomegranate peel—Spirulina: $50 / 50 \%) . \pm$ : standard deviation of the mean; values with a different letter (a-d) of the same chemical properties or phytochemical content are significantly different $(p<0.05)$.

The protein content of the studied samples varied significantly $(p<0.05)$ between 7.68 and $69.54 \%$ (Table 1). Spirulina (S2) has the highest $(p<0.05)$ protein content $(69.54 \%)$ compared to S1, S3 and S4. These contents are also higher than those found in other Spirulina strains [34,35]. Amongst others proteins, phycocyanin is a blue coloring agent applied in the food industry and cosmetics, stands out with a well-established antioxidant capacity [36].

For S1 sample, protein content was higher than those found in other Tunisian cultivars 'Acide' (3.96\%), 'Nebli' (5.42\%) and 'Tounsi' (5.84\%) [32], as well as other Turkish cultivars, 'Lefon', 'Seedless', 'Kadi', 'Siyah' and 'Koycegiz', whose contents are 3.19; 3.11; 3.06; 2.67 and 2.58\%, respectively [37]. The protein content in S3 sample $(54.52 \%)$ was found to be higher $(p<0.05)$ than the other combined sample (S4: $37.42 \%)$.

As presented in the Table 1, S2 sample showed the highest $(p<0.05)$ total lipid content (TLC) of $7.18 \%$, for the other samples TLC values were about $0,5.15$ and 2.75 for S1, S3 and S4, respectively. In accordance with our results, Bensehaila et al. [35] found a similar TLC of 7.28\% for a Spirulina platensis strain. However, in the same condition of growth, Algerian Spirulina showed lower lipid content [33]. According to Capelli and Cysewski [38], the lipid content in Spirulina ranged between 5 and 8\%, but as reported by Babadzhanov et al. [39], it could reach 14.3\% in an Uzbekistan Spirulina platensis strain. This variability could be related to the differences in culture conditions. In the same context, Richmond [40] reported that microalgae lipid production depends on the species and their culture conditions such as nutrients, salinity, light intensity, temperature, $\mathrm{pH}$ and even the association with other microorganisms.

The total ash content of studied samples was between $5.02 \%$ and $10.69 \%$, for S1 and S2 samples respectively. The concentration of ash found in pomegranate peels (S1) was higher than that reported by Abid et al. [32], ranging between $3.71 \%$ and $4.97 \%$, and lower than the values presented by Romelle et al. [41]. As shown in the Table 1, Spirulina samples (S2) showed ash percentage of $10.69 \%$; this value was comparable to $A$. platensis from Algeria and higher compared with previous work by Bensehaila et al. [35]. 


\subsection{Phytochemical Content}

Concerning the phytochemical content, comparison between the four samples showed that TPC in S1 was significantly higher $(p<0.05)$ than those in S2, S3 and S4. Levels of TPCs ranged between 4.59 and $131.14 \mathrm{mg} \mathrm{GAE} / \mathrm{g}$ of dried sample (Table 1). The best TPC (131.14 mg GAE/g of extract) was obtained from the S1 sample, consistent with previous studies [32], the TPCs of four ethanolic extracts from different Tunisian ecotypes ranged between 109.21 and $140.93 \mathrm{mg} \mathrm{GAE} / \mathrm{g}$. For S2 samples, results indicated the presence of TPC at a concentration of $4.59 \mathrm{mg} \mathrm{GAE} / \mathrm{g}$. This value was higher than those found in other studies reported by De Marco et al. [42], Gargouri et al. [43] where the authors demonstrated that the TPCs were, respectively, 4.08, 3.4 and $2.49 \mathrm{mg} \mathrm{GAE} / \mathrm{g}$. As shown in Table 1, the determination of major classes of secondary compounds in S1, S3 and S4 extracts indicated that phenolic compounds were high in anthocyanins at $18.7 \%, 17.01 \%$ and $18.00 \%$, respectively, while Spirulina (S2) was rich in flavonoids (59.91\%). Gargouri et al. [43] reported that Spirulina has high amount of flavonoids with TFC/TPC ratios of $35.29 \%$ and $76.30 \%$, respectively.

\subsection{Antifungal Activity against Plant Pathogenic Fungi}

Various pathogenic fungi infect plants leading to the reduction in yield and quality crop, and the contamination of grains with fungal mycotoxins. Therefore, we have evaluated the antifungal activities of S1, S2, S3 and S4 against five fungal plant pathogens namely F. oxysporum, F. culmorum, F. graminearum, Alternaria alternata and Aspergillus niger.

As shown in Table 2, the antifungal test demonstrated that pomegranate peel (S1) produced antifungal compounds against a variety of phytopathogenic fungi from different classes. A moderate but significant $(p<0.05)$ inhibitory effect of S1 on the growth of Aspergillus niger CTM 10099 with an inhibition zone of $14 \mathrm{~mm}$ was observed. In 2009, Al-Zoreky [44] reported that several fungal species, such as Aspergillus niger, were sensitive to pomegranate fruit peel water/methanol extract, however, the inhibitory effect of pomegranate water extracts have not been studied against this fungi. In earlier studies, Azzouz and Bullerman [45] in 1982 reported that pomegranate peel extract have no effect on the growth of Aspergillus flavus and Aspergillus parasiticus. More recently, Rongai et al. [46] reported in 2017 that aqueous extract of pomegranate peel showed a wide spectrum of antifungal activities especially against Fusarium oxysporum.

Table 2. Antifungal activity of of Spirulina platensis and its combinations with pomegranate peel against plant pathogenic fungi: Fusarium oxysporum, Fusarium culmorum, Fusarium graminearum, Aspergillus niger and Alternaria alternata strains.

\begin{tabular}{|c|c|c|c|c|c|}
\hline \multirow{2}{*}{ Fungal Strains } & \multicolumn{5}{|c|}{ Inhibition Zones Diameters (mm) } \\
\hline & S1 & S2 & S3 & S4 & Amphotericin B \\
\hline $\begin{array}{l}\text { Fusarium oxysporum } \\
\text { (CTM10402) }\end{array}$ & $12.25 \pm 0.25^{\mathrm{aB}}$ & $15.75 \pm 0.75^{\mathrm{abB}}$ & $22.25 \pm 0.50^{\mathrm{dB}}$ & $16.25 \pm 0.50^{\mathrm{cC}}$ & $14.25 \pm 0.25 \mathrm{bB}$ \\
\hline $\begin{array}{l}\text { Fusarium culmorum } \\
\text { (ISPAVE } 21 \mathrm{w})\end{array}$ & $10.00 \pm 0.75^{\mathrm{aA}}$ & $15.00 \pm 0.33^{\mathrm{bB}}$ & $21.75 \pm 0.33^{\mathrm{dB}}$ & $15.00 \pm 0.33^{c B}$ & $12.50 \pm 0.75^{\mathrm{bA}}$ \\
\hline $\begin{array}{l}\text { Fusarium graminearum } \\
\text { (ISPAVE 271) }\end{array}$ & $11.75 \pm 0.33 \mathrm{aAB}$ & $15.25 \pm 0.38^{\mathrm{bB}}$ & $24.75 \pm 0.33 \mathrm{dC}$ & $12.75 \pm 0.50 \mathrm{bA}$ & $14.75 \pm 0.50^{c}$ \\
\hline $\begin{array}{l}\text { Aspergillus niger } \\
\text { (CTM 10099) }\end{array}$ & $14.00 \pm 0.83^{\mathrm{aC}}$ & $11.25 \pm 0.66^{\mathrm{bC}}$ & $18.25 \pm 0.75^{\mathrm{cA}}$ & $14.75 \pm 0.38^{a b B}$ & $15.25 \pm 0.83^{b C}$ \\
\hline $\begin{array}{l}\text { Alternaria alternata } \\
\text { (CTM 10230) }\end{array}$ & $11.75 \pm 0.66^{\mathrm{aAB}}$ & $10.25 \pm 0.25^{\mathrm{aA}}$ & $19.25 \pm 0.83^{\mathrm{cA}}$ & $14.25 \pm 0.66^{\mathrm{bB}}$ & $14.75 \pm 0.66^{\mathrm{bBC}}$ \\
\hline
\end{tabular}

S1 (pomegranate peel), S2 (Spirulina), S3 (pomegranate peel-Spirulina: 25\%/75\%) and S4 (pomegranate peel—Spirulina: $50 \% / 50 \%)$. \pm : standard deviation of the mean; inhibition zones diameters $(\mathrm{mm})$ with a different letter $(\mathrm{a}-\mathrm{d})$ of the same fungal strain are significantly different $(p<0.05)$; Inhibition zones diameters $(\mathrm{mm})$ with a different letter $(\mathrm{A}-\mathrm{C})$ of the same extract are significantly different. 
Equally, as illustrated in the Table 2, we have demonstrated the capacity of Spirulina (S2) to inhibit all the studied panel of fungal strains, particularly Fusarium genus. In fact, this antifungal activity was similar to standard synthetic antifungal agent (Amphotericin B). Similarly, Al-Ghanayem [47], reported the inhibition growth of Fusarium oxysporum followed by Aspergillus flavus and Aspergillus niger by Spirulina platensis organic extract. Furthermore, Kumar et al. in 2011 reported the inhibitory effect of hexane and methanolic extracts of Spirulina platensis against Aspergillus spp. [48]. The activity of the alga could be due to the intracellular and extracellular metabolites that have antifungal properties [47]. In general, it was demonstrated that the most antifungal compounds in Spirulina are mainly polyphenols along with polysaccharides that inhibit microbial growth, or directly by destroying the living structures of fungi [49]. Compared to S1, S2 and S4, Amphotericin B had higher antifungal activity against Aspergillus niger CTM 10099 and Alternaria alternata CTM 10230. Concerning anti Fusarium activity, Spirulina (S1) had a significantly $(p<0.05)$ lower inhibition zone compared to Amphotericin B (Table 2).

Interestingly, the extract S3 revealed a strong $(p<0.05)$ antifungal activity against all tested species, and the distance of the inhibitory zone varied from $18.25-24.75 \mathrm{~mm}$ (Table 2). The Fusarium graminearum ISPAVE 271, was the most susceptible with an inhibition zone of $24.75 \mathrm{~mm}$ followed by Fusarium oxysporum CTM10402, Fusarium culmorum ISPAVE 21w, Alternaria alternata CTM 10230 and Aspergillus niger CTM 10099. S3 showed a strong activity against mycotoxigenic and phytopathogenic fungi, notably against F. graminearum, F. oxysporum and F. culmorum producing type B trichothecene mycotoxins, nivalenol (NIV), deoxynivalenol (DON) and their acetylated derivatives. However, moderate activity was found against Aspergillus niger the main ochratoxin A (OTA) producer (Table 2).

\subsection{MIC and MFC Determination}

The quantitative evaluation of the antifungal activity of S1, S2, S3 and S4 extracts was carried out. The effect of each extracts on the growth of all fungal strains was thus tested at different concentrations $(0.078-20 \mathrm{mg} / \mathrm{mL})$. The MIC and the MFC were determined and ratio of MFC/MIC was obtained (Table 3). The observed MIC values of the S1 (pomegranate peel) extract showed same values for the three strains: Fusarium culmorum ISPAVE 21w, Fusarium graminearum ISPAVE 271 and Alternaria alternata CTM 10230 strains $(0.312 \mathrm{mg} / \mathrm{mL}$ ), while S2 (Spirulina) extract MIC value was about $0.156 \mathrm{mg} / \mathrm{mL}$ for all three strains. Some differences could be observed with previously reported literature. For example, Usharani et al. in 2015 stated that the ethanloic Spirulina extracts exhibited antifungal activity against A. niger at concentrations of 16,35 and $>35 \mathrm{mg} / \mathrm{mL}$ [50]. The MFC/MIC ratio was also calculated and an agent was considered fungicidal if the minimal fungicidal concentration (MFC) to minimal inhibitory concentration (MIC) ratio was $\leq 4$ and fungistatic if the ratio was $>4$. MFC/MIC ratio indicated that S3 and S4 extracts showed interesting fungicidal effects on all studied pathogens fungi (Table 3). Comparing the mean of MIC and MFC values of all tested fungi strains, S3 and S4 exhibited approximately two times stronger inhibition than S1 and S2. Remarkably, S3 and S4 extracts exhibited the lowest ratio MFC/MIC values against all fungi with a value equal to 2 (Table 3 ). The combination of Spirulina and pomegranate peel extracts showed a synergistic antifungal effect against all fungal strains. According to these observations, strong antifungal activity could be attributed to phenolic compounds (Table 1). Possible modes of action of phenolic compounds have been reported in different reviews [51-54], however the mechanisms have not been completely elucidated. López-Malo et al. in 2005 mentioned that the effect of phenolic compounds is concentration-dependent [51]. The authors reported that, at low concentration, phenols could affect enzyme activity negatively, especially of those associated with energy production, while at greater concentrations, protein denaturation could occur [51]. The effect of phenolic compounds on fungal growth and toxin production could be the result of cell permeability alteration, permitting the loss of macromolecules from the interior. They could also interact with membrane proteins, causing a deformation in their structure and functionality [51]. Once the phenolic compound crossed the cellular membrane, interactions with membrane enzymes and proteins would cause an opposite flow of protons, affecting cellular activity [51-54]. 
Table 3. Minimal inhibitory concentration (MIC) and minimal fungicidal concentration (MFC) values of Spirulina platensis and its combinations with pomegranate peel against Fusarium oxysporum, Fusarium culmorum, Fusarium graminearum, Aspergillus niger and Alternaria alternata strains.

\begin{tabular}{cccccc}
\hline & Extract & MIC & MFC & Ratio MFC/MIC & Interpretation \\
\hline \multirow{2}{*}{ Fusarium oxysporum } & S1 & 0.312 & 1.250 & 4 & Fungicidal \\
(CTM10402) & S2 & 0.156 & 0.625 & 4 & Fungicidal \\
& S3 & 0.078 & 0.156 & 2 & Fungicidal \\
& S3 & 0.156 & 0.312 & 2 & Fungicidal \\
\hline Fusarium culmorum & S1 & 0.312 & 1.250 & 4 & Fungicidal \\
ISPAVE 21w & S2 & 0.156 & 0.625 & 4 & Fungicidal \\
& S3 & 0.078 & 0.156 & 2 & Fungicidal \\
& S4 & 0.078 & 0.156 & 2 & Fungicidal \\
\hline \multirow{2}{*}{ Fusarium graminearum } & S1 & 0.312 & 1.250 & 4 & Fungicidal \\
ISPAVE 271 & S2 & 0.156 & 1.250 & 8 & Fungistatic \\
& S3 & 0.078 & 0.156 & 2 & Fungicidal \\
& S4 & 0.078 & 0.156 & 2 & Fungicidal \\
\hline Aspergillus niger CTM & S1 & 1.250 & 5 & 4 & Fungicidal \\
10099 & S2 & 0.625 & 2.5 & 4 & Fungicidal \\
& S3 & 0.312 & 0.625 & 2 & Fungicidal \\
& S4 & 0.312 & 0.625 & 2 & Fungicidal \\
\hline Alternaria alternata & S1 & 0.312 & 1.250 & 4 & Fungicidal \\
CTM 10230 & S2 & 0.156 & 0.312 & 2 & Fungicidal \\
& S3 & 0.078 & 0.156 & 2 & Fungicidal \\
& S4 & 0.156 & 0.312 & 2 & Fungicidal \\
\hline
\end{tabular}

S1 (pomegranate peel), S2 (Spirulina), S3 (pomegranate peel-Spirulina: 25\%/75\%) and S4 (pomegranate peel-Spirulina: $50 \% / 50 \%)$.

\subsection{Relationships between Phytochemical Content of Pomegranate Peel, Spirulina and Their Combinations and} Antifungal Activities

The correlation between phytochemical content (TPC, TFC and TAC) and antimycotoxigenic fungal activities was investigated. Therefore, as shown in Table 4, for S1 samples, a significant negative correlation was found between TPC, TAC and five mycotoxigenic fungi. This negative correlation was more significant for TAC in anti F. oxysporum CTM10402 $(r=-0.708, p<0.05)$, anti F. culmorum ISPAVE 21w $(r=-0.861, p<0.01)$ and A. niger CTM $10099(r=-0.837, p<0.05)$ samples. These data consolidate our results shown in Table 1 , in which the phenolic compounds (TFC) were rich in anthocyanins (TAC) for $\mathrm{S} 1$ samples. Our results are in agreement with those previously reported by Glazer et al. [55] where a correlations between TFC and the growth rates of A. alternata $(\mathrm{r}=-0.85, p<$ $0.01)$ and Fusarium spp., $(\mathrm{r}=-0.89, p<0.05)$ was found. It is known that TPC, TAC and antibacterial activity are usually well correlated in red color-anthocyanin rich fruits [56]. Furthermore, contrary to the study of Duman et al. [57], no significant correlation $(p>0.05)$ was found between TPC, TAC and the yeast Candida albicans. As presented in Table 4, a significant positive correlation was found between TPC, TFC and all fungi strains. In fact, for S2 samples, the TFC content showed a strong correlation $(p<0.01)$ with the anti F. graminearum ISPAVE $271(r=0.983)$, anti A. alternate CTM $10230(r=0.983)$ and anti $A$. niger CTM 10099 ( $r=0.878)$. In our case, the use of raw phenolic extract from Spirulina sp. and pomegranate peel in combination (S3 and S4) exhibited promising growth inhibitory profile against fungal strains. The phenolic group joined to a single hydroxyl group confers lipophilicities and acidity, important factors in antifungal activity [58]. Phenolic compounds primarily synthesized through the pentose phosphate pathway (PPP), shikimate and phenylpropanoid pathways. The oxidative PPP provides erythrose-4-phosphate precursor for the shikimate pathway which converts these sugar phosphates to aromatic amino acids like phenylalanine, which becomes the precursor for the phenylpropanoid pathway. This pathway is responsible for the synthesis of a wide variety of phenolic compounds [59] and plays a vital role in plant growth, regulation of plant metabolism, 
lignin synthesis and exhibit pharmacological properties such as antitumor, antiviral, antiinflammatory, hypotensive and antifungal activity $[59,60]$.

Table 4. Pearson's correlation coefficients between the antimicrobial (antibacterial and antifungal) activity and the phytochemical contents.

\begin{tabular}{|c|c|c|c|c|}
\hline Fungi Strains & & TPC & TFC & TAC \\
\hline \multirow{4}{*}{ F. oxysporum CTM10402 } & S1 & $-0.700 *$ & 0.006 & $-0.708 *$ \\
\hline & S2 & $0.673 *$ & $0.687^{*}$ & -0.172 \\
\hline & S3 & $0.878^{* *}$ & 0.408 & $-0.675^{*}$ \\
\hline & S4 & $0.723 *$ & 0.088 & $-0.622 *$ \\
\hline \multirow{4}{*}{ F. culmorum ISPAVE $21 \mathrm{w}$} & S1 & -0.774 * & 0.640 & $-0.861 * *$ \\
\hline & S2 & $0.763 *$ & $0.641 *$ & -0.259 \\
\hline & S3 & $0.878 * *$ & 0.408 & $-0.675 *$ \\
\hline & S4 & $0.956 * *$ & 0.457 & $-0.664 *$ \\
\hline \multirow{4}{*}{ F. graminearum ISPAVE 271} & S1 & $-0.809 *$ & 0.268 & $-0.756^{*}$ \\
\hline & S2 & $0.652 *$ & $0.983 * *$ & -0.335 \\
\hline & S3 & $0.994 * *$ & $0.809 *$ & $-0.747 *$ \\
\hline & S4 & $0.681 *$ & $0.760 *$ & -0.157 \\
\hline \multirow{4}{*}{ A. niger CTM 10099} & S1 & -0.732 * & 0.595 & $-0.837 *$ \\
\hline & S2 & $0.738 *$ & $0.878 * *$ & -0.404 \\
\hline & S3 & $0.700 *$ & $0.981 * *$ & $-0.743 *$ \\
\hline & S4 & 0.670 * & $0.726^{*}$ & $-0.664 *$ \\
\hline \multirow{4}{*}{ A. alternata CTM 10230} & S1 & -0.758 * & 0.311 & $-0.700 *$ \\
\hline & S2 & $0.752 *$ & $0.983 * *$ & -0.335 \\
\hline & S3 & $0.923 * *$ & $0.758 *$ & -0.284 \\
\hline & S4 & $0.904 * *$ & $0.657 *$ & -0.534 \\
\hline
\end{tabular}

${ }^{*}: p<0.05 ;{ }^{* *}: p<0.01$; Notes: The most significant loadings are highlighted in bold.

For S3 and S4 samples, a significant correlation was found between: (F. graminearum ISPAVE 271, TPC, TFC and TAC) and (A. niger CTM 10099 and all phytochemical contents). For S3 samples, F. oxysporum CTM10402 and F. culmorum ISPAVE 21w were only correlated with TPC and TAC (Table 4), while A. alternata CTM 10230 was correlated with TFC $(r=-0.758, p<0.05)$. Interestingly, for the S4 sample, anti $A$. niger CTM 10099 activity had a high correlation with TPC $(r=0.670, p<0.05)$; TFC $(r=0.726, p<0.05)$ and TAC $(r=-0.664, p<0.05)$. Equally, as shown in the Table 4 , a strong relationship was found between anti A. alternata CTM 10230 activity, TPC $(r=0.904, p<0.01)$ and TFC $(r=0.657, p<0.05)$. Thus, the synergistic effects, and the diversity of TPC, TFC and TAC presented in the combination of pomegranate peel and spirulina ethanolic extracts should be taken into account for their antifungal activities.

\section{Conclusions}

Spirulina and pomegranate peel extracts alone and in combination were chemically characterized and then evaluated for their antifungal activities against Fusarium, Aspergillus and Alternaria genera. Correlations between these antifungal activities and phytochemical content were evaluated. The results showed that the combination between Spirulina at 75\% and pomegranate peel at 25\% (S3) have a significant impact $(p<0.05)$ on the antifungal activity compared to S1, S2 and S4. Finally, Pearson correlation demonstrated that S3 polyphenols were mostly responsible for tested antimycotoxigenic and antiphytopathogenic fungal properties. Therefore, bioactive molecules of Spirulina and pomegranate peel combination could be used as a safe method against plant pathogenic fungi. To the best of our knowledge, this is the first work reporting the combination of algae and a plant by-product to enhance the antifungal activity. 
Author Contributions: Conceptualization, H.B.H. and T.B.; methodology, H.B.H.; software, S.S.; validation, S.A., P.M., A.O. and L.M.; formal analysis, H.B.H.; investigation, M.K.; resources, T.B.; data curation, M.K. and S.S.; writing-original draft preparation, H.B.H. and S.S.; writing-review and editing, H.B.H.; supervision, P.M., S.A., A.O. and L.M.; project administration, T.B.

Funding: This research received no external funding

Acknowledgments: This project is carried out in part under the MOBIDOC scheme, funded by the EU through the EMORI program and managed by the ANPR.

Conflicts of Interest: The authors declare no conflict of interest.

\section{References}

1. Kim, B.; Han, J.W.; Ngo, M.T.; Le Dang, Q.; Kim, J.C.; Kim, H.; Choi, G.J. Identification of novel compounds, oleanane-and ursane-type triterpene glycosides, from Trevesia palmata: Their biocontrol activity against phytopathogenic fungi. Sci. Rep. 2018, 8, 14522-14532. [CrossRef] [PubMed]

2. Tetz, G.; Collins, M.; Vikina, D.; Tetz, V. In vitro activity of a novel antifungal compound, MYC-053, against clinically significant antifungal-resistant strains of Candida glabrata, Candida auris, Cryptococcus neoformans, and Pneumocystis spp. Antimicrob. Agents Chemother. 2019, 63, e01975-18. [CrossRef] [PubMed]

3. Dubey, S.; Sillanpaa, M.; Varma, R. Reduction of hexavalent chromium using Sorbaria sorbifolia aqueous leaf extract. Appl. Sci. 2017, 7, 715. [CrossRef]

4. Mtibaa, A.C.; Smaoui, S.; Ben Hlima, H.; Sellem, I.; Ennouri, K.; Mellouli, L. Enterocin BacFL31 from a safety Enterococcus faecium FL31: Natural preservative agent used alone and in combination with aqueous peel onion (Allium cepa) extract in ground beef meat storage. BioMed Res. Int. 2019, 2019, 4094890. [CrossRef] [PubMed]

5. Fendri, I.; Chamkha, M.; Bouaziz, M.; Labat, M.; Sayadi, S.; Abdelkafi, S. Olive fermentation brine: Biotechnological potentialities and valorization. Environ. Technol. 2013, 34, 181-193. [CrossRef] [PubMed]

6. Fourati, M.; Smaoui, S.; Ennouri, K.; Ben Hlima, H.; Elhadef, K.; Chakchouk-Mtibaa, A.; Sellem, I.; Mellouli, L. Multiresponse optimization of pomegranate peel extraction by statistical versus artificial intelligence: Predictive approach for foodborne bacterial pathogen inactivation. Evid. Based Complement. Alternat. Med. 2019, 2019, 1542615. [CrossRef]

7. Smaoui, S.; Hlima, H.B.; Mtibaa, A.C.; Fourati, M.; Sellem, I.; Elhadef, K.; Ennouri, K.; Mellouli, L. Pomegranate peel as phenolic compounds source: Advanced analytical strategies and practical use in meat products. Meat Sci. 2019, 158, 107914-107933. [CrossRef]

8. Fourati, M.; Smaoui, S.; Ben Hlima, H.; Ennouri, K.; Chakchouk Mtibaa, A.; Sellem, I.; Elhadef, K.; Mellouli, L. Synchronised interrelationship between lipid/protein oxidation analysis and sensory attributes in refrigerated minced beef meat formulated with Punica granatum peel extract. Int. J. Food Sci. Technol. 2019. [CrossRef]

9. Šavikin, K.; Živković, J.; Alimpić, A.; Zdunić, G.; Janković, T.; Duletić-Laušević, S.; Menković, N. Activity guided fractionation of pomegranate extract and its antioxidant, antidiabetic and antineurodegenerative properties. Ind. Crop. Prod. 2018, 113, 142-149. [CrossRef]

10. Singh, B.; Singh, J.P.; Kaur, A.; Singh, N. Antimicrobial potential of pomegranate peel: A review. Int. J. Food Sci. Technol. 2019, 54, 959-965. [CrossRef]

11. Kharchoufi, S.; Licciardello, F.; Siracusa, L.; Muratore, G.; Hamdi, M.; Restuccia, C. Antimicrobial and antioxidant features of 'Gabsi' pomegranate peel extracts. Ind. Crop Prod. 2018, 111, 345-352. [CrossRef]

12. Moreno, M.A.; Córdoba, S.; Zampini, I.C.; Mercado, M.I.; Ponessa, G.; Alberto, M.R.; Fatima Nader-Macias, M.E.; Sayago, J.; Burgos-Edwards, A.; Schmeda-Hirschmann, G.; et al. Tetraglochin andina Ciald.: A medicinal plant from the Argentinean highlands with potential use in vaginal candidiasis. J. Ethnopharmacol. 2018, 216, 283-294. [CrossRef] [PubMed]

13. Tayel, A.A.; Salem, M.F.; El-Tras, W.F.; Brimer, L. Exploration of Islamic medicine plant extracts as powerful antifungals for the prevention of mycotoxigenic Aspergilli growth in organic silage. J. Sci. Food Agric. 2011, 91, 2160-2165. [CrossRef] [PubMed]

14. Osorio, E.; Flores, M.; Hernández, D.; Ventura, J.; Rodríguez, R.; Aguilar, C.N. Biological efficiency of polyphenolic extracts from pecan nuts shell (Carya Illinoensis), pomegranate husk (Punica granatum) and creosote bush leaves (Larrea tridentata Cov.) against plant pathogenic fungi. Ind. Crop Prod. 2010, 31, 153-157. [CrossRef] 
15. Tehranifar, A.; Selahvarzi, Y.; Kharrazi, M.; Bakhsh, V.J. High potential of agro-industrial by-products of pomegranate (Punica granatum L.) as the powerful antifungal and antioxidant substances. Ind. Crop Prod. 2011, 34, 1523-1527. [CrossRef]

16. Nowicka, A.; Zieliński, M.; Debowski, M. Microwave support of the alcoholic fermentation process of cyanobacteria Arthrospira platensis. Proceedings 2018, 2, 1315. [CrossRef]

17. Eleiwa, N.Z.; Galal, A.A.; El-Aziz, R.M.A.; Hussin, E.M. Antioxidant activity of Spirulina platensis alleviates doxorubicin-induced oxidative stress and reprotoxicity in male rats. Orient Pharm. Exp. Med. 2018, 18, 87-95. [CrossRef]

18. Marangoni, A.; Foschi, C.; Micucci, M.; Palomino, R.A.N.; Toschi, T.G.; Vitali, B.; Camarada, L.; Mandrioli, M.; De Georgio, M.; Aldini, R.; et al. In vitro activity of Spirulina platensis water extract against different Candida species isolated from vulvo-vaginal candidiasis cases. PLoS ONE 2017, 12, e0188567. [CrossRef]

19. Choi, W.Y.; Sim, J.-H.; Lee, J.-Y.; Kang, D.H.; Lee, H.Y. Increased anti-Inflammatory effects on LPS-Induced microglia cells by Spirulina maxima extract from ultrasonic process. Appl. Sci. 2019, 9, 2144. [CrossRef]

20. Sarada, R.M.G.P.; Pillai, M.G.; Ravishankar, G.A. Phycocyanin from Spirulina sp: Influence of processing of biomass on phycocyanin yield, analysis of efficacy of extraction methods and stability studies on phycocyanin. Process Biochem. 1999, 34, 795-801. [CrossRef]

21. AOAC. Association of Official Analytical Chemists Official Methods of Analysis: Changes in Official Methods of Analysis Made at the Annual Meeting. Supplement 1990; Association of Official Analytical Chemists: Washington, DC, USA, 1990; Volume 15.

22. Fendri, I.; Ben Saad, R.; Khemakhem, B.; Ben Halima, N.; Gdoura, R.; Abdelkafi, S. Effect of treated and untreated domestic wastewater on seed germination, seedling growth and amylase and lipase activities in Avena sativa L. J. Sci. Food Agric. 2013, 93, 1568-1574. [CrossRef] [PubMed]

23. AFNOR NF 03-713. Céréales et Produits Céréaliers; Association Française de Normalisation: Paris, France, 1984.

24. Lahaye, M.; Jegou, D. Chemical and physical-chemical characteristics of dietary fibres from Ulva lactuca (L.) Thuret and Enteromorpha compressa (L.) Grev. J. Appl. Phycol. 1993, 5, 195. [CrossRef]

25. Singleton, V.L.; Rossi, J.A. Colorimetry of total phenolics with phosphomolybdic-phosphotungstic acid reagents. Am. J. Enol. Viticult. 1965, 16, 144-158.

26. Quettier-Deleu, C.; Gressier, B.; Vasseur, J.; Dine, T.; Brunet, C.; Luyckx, M.; Cazin, M.; Cazin, J.C.; Bailleul, F.; Trotin, F. Phenolic compounds and antioxidant activities of buckwheat (Fagopyrum esculentum Moench) hulls and flour. J. Ethnopharmacol. 2000, 72, 35-42. [CrossRef]

27. Li, X.; Zhang, J.Y.; Gao, W.Y.; Wang, Y.; Wang, H.Y.; Cao, J.G.; Huang, L.Q. Chemical composition and anti-inflammatory and antioxidant activities of eight pear cultivars. J. Agric. Food. Chem. 2012, 60, 8738-8744. [CrossRef]

28. Smaoui, S.; Ennouri, K.; Chakchouk-Mtibaa, A.; Sellem, I.; Bouchaala, K.; Karray-Rebai, I.; Mellouli, L. Statistical versus artificial intelligence-based modeling for the optimization of antifungal activity against Fusarium oxysporum using Streptomyces sp. strain TN71. J. Mycol. Med. 2018, 28, 551-560. [CrossRef]

29. Smaoui, S.; Mellouli, L.; Lebrihi, A.; Coppel, Y.; Fguira, L.F.B.; Mathieu, F. Purification and structure elucidation of three naturally bioactive molecules from the new terrestrial Streptomyces sp. TN17 strain. Nat. Prod. Res. 2011, 25, 806-814. [CrossRef]

30. Talibi, I.; Askarne, L.; Boubaker, H.; Boudyach, E.H.; Msanda, F.; Saadi, B.; Aoumar, A.A.B. Antifungal activity of some Moroccan plants against Geotrichum candidum, the causal agent of postharvest citrus sour rot. Crop Prot. 2012, 35, 41-46. [CrossRef]

31. Spórna-Kucab, A.; Bernaś, K.; Grzegorczyk, A.; Malm, A.; Skalicka-Woźniak, K.; Wybraniec, S. Liquid chromatographic techniques in betacyanin isomers separation from Gomphrena globosa L. flowers for the determination of their antimicrobial activities. J. Pharmaceut. Biomed. 2018, 161, 83-93. [CrossRef]

32. Abid, M.; Yaich, H.; Cheikhrouhou, S.; Khemakhem, I.; Bouaziz, M.; Attia, H.; Ayadi, M.A. Antioxidant properties and phenolic profile characterization by LC-MS/MS of selected Tunisian pomegranate peels. J. Food Sci. Technol. 2017, 54, 2890-2901. [CrossRef]

33. Aouir, A.; Amiali, M.; Bitam, A.; Benchabane, A.; Raghavan, V.G. Comparison of the biochemical composition of different Arthrospira platensis strains from Algeria, Chad and the USA. J. Food Meas. Charact. 2017, 11, 913-923. [CrossRef] 
34. Morais, E.G.D.; Cassuriaga, A.P.A.; Callejas, N.; Martinez, N.; Vieitez, I.; Jachmanián, I.; Santos, L.O.; De Morais, M.G.; Costa, J.A.V. Evaluation of $\mathrm{CO}_{2}$ biofixation and biodiesel production by Spirulina (Arthospira) cultivated in air-lift photobioreactor. Braz. Arch. Biol. Technol 2018, 61, e18161339. [CrossRef]

35. Bensehaila, S.; Doumandji, A.; Boutekrabt, L.; Manafikhi, H.; Peluso, I.; Bensehaila, K.; Kouache, A.; Bensehaila, A. The nutritional quality of Spirulina platensis of Tamenrasset, Algeria. Afr. J. Biotechnol. 2015, 14, 1649-1654. [CrossRef]

36. Bai, S.; Dai, J.; Xia, M.; Ruan, J.; Wei, H.; Yu, D.; Li, R.; Jing, H.; Tian, C.; Song, L.; et al. Effects of intermediate metabolite carboxylic acids of TCA cycle on Microcystis with overproduction of phycocyanin. Environ. Sci. Pollut. Res. 2015, 22, 5531-5537. [CrossRef]

37. Hepaksoy, S.; Aksoy, U.; Can, H.Z.; Ui, M.A. Determination of relationship between fruit cracking and some physiological responses, leaf characteristics and nutritional status of some pomegranate varieties. Cah. Options Méditerranénnes 2000, 42, 87-92.

38. Capelli, B.; Cysewski, G.R. Potential health benefits of spirulina microalgae. Nutrafoods 2010, 9, 19-26. [CrossRef]

39. Babadzhanov, A.S.; Abdusamatova, N.; Yusupova, F.M.; Faizullaeva, N.; Mezhlumyan, L.G.; Malikova, M.K. Chemical composition of Spirulina platensis cultivated in Uzbekistan. Chem. Nat. Compd. 2004, 40, $276-279$. [CrossRef]

40. Richmond, A. (Ed.) Handbook of Microalgal Culture: Biotechnology and Applied Phycology; Blackwell Science: Oxford, UK, 2004; Volume 577.

41. Romelle, F.D.; Rani, P.A.; Manohar, R.S. Chemical composition of some selected fruit peels. Eur. J. Food. Sci. Technol. 2016, 4, 12-21.

42. De Marco, E.R.; Steffolani, M.E.; Martínez, C.S.; León, A.E. Effects of spirulina biomass on the technological and nutritional quality of bread wheat pasta. LWT Food Sci. Technol. 2014, 58, 102-108. [CrossRef]

43. Gargouri, M.; Magné, C.; El Feki, A. Hyperglycemia, oxidative stress, liver damage and dysfunction in alloxan-induced diabetic rat are prevented by Spirulina supplementation. Nutr. Res. 2016, 36, 1255-1268. [CrossRef]

44. Al-Zoreky, N.S. Antimicrobial activity of pomegranate (Punica granatum L.) fruit peels. Int. J. Food Microbiol. 2009, 134, 244-248. [CrossRef] [PubMed]

45. Azzouz, M.A.; Bullerman, L.B. Comparative antimycotic effects of selected herbs, spices, plant components and commercial antifungal agents. J. Food Protect. 1982, 45, 1298-1301. [CrossRef] [PubMed]

46. Rongai, D.; Pulcini, P.; Pesce, B.; Milano, F. Antifungal activity of pomegranate peel extract against fusarium wilt of tomato. Eur. J. Plant Pathol. 2017, 147, 229-238. [CrossRef]

47. Al-ghanayem, A.A. Antimicrobial activity of Spirulina platensis extracts against certain pathogenic bacteria and fungi. Adv. Biores. 2017, 8, 96-101. [CrossRef]

48. Kumar, V.; Bhatnagar, A.K.; Srivastava, J.N. Antibacterial activity of crude extracts of Spirulina platensis and its structural elucidation of bioactive compound. J. Med. Plants Res. 2011, 5, 7043-7048. [CrossRef]

49. Bajpai, V.K. Antimicrobial bioactive compounds from marine algae: A mini review. Indian J. Geomar. Sci. 2016, 45, 1076-1085.

50. Usharani, G.; Srinivasan, G.; Sivasakthi, S.; Saranraj, P. Antimicrobial activity of Spirulina platensis solvent extracts against pathogenic bacteria and fungi. Adv. Biol. Res. 2015, 9, 292-298. [CrossRef]

51. López-Malo, A.; Alzamora, S.M.; Palou, E. Aspergillus flavus growth in the presence of chemical preservatives and naturally occurring antimicrobial compounds. Int. J. Food Microbiol. 2005, 99, 119-128. [CrossRef] [PubMed]

52. Da Cruz Cabral, L.; Pinto, V.F.; Patriarca, A. Application of plant derived compounds to control fungal spoilage and mycotoxin production in foods. Int. J. Food Microbiol. 2013, 166, 1-14. [CrossRef]

53. Pillai, P.; Ramaswamy, K. Effect of naturally occurring antimicrobials and chemical preservatives on the growth of Aspergillus parasiticus. J. Food Sci. Technol. 2012, 49, 228-233. [CrossRef]

54. Arokiyaraj, S.; Bharanidharan, R.; Agastian, P.; Shin, H. Chemical composition, antioxidant activity and antibacterial mechanism of action from Marsilea minuta leaf hexane: Methanol extract. Chem. Cent. J. 2018, 12, 105-115. [CrossRef] [PubMed]

55. Glazer, I.; Masaphy, S.; Marciano, P.; Bar-Ilan, I.; Holland, D.; Kerem, Z.; Amir, R. Partial identification of antifungal compounds from Punica granatum peel extracts. J. Agric. Food Chem. 2012, 60, 4841-4848. [CrossRef] [PubMed] 
56. Özgen, M.; Serçe, S.; Kaya, C. Phytochemical and antioxidant properties of anthocyanin-rich Morus nigra and Morus rubra fruits. Sci. Hortic. 2009, 119, 275-279. [CrossRef]

57. Duman, A.; Ozgen, M.; Dayisoylu, K.; Erbil, N.; Durgac, C. Antimicrobial activity of six pomegranate (Punica granatum L.) varieties and their relation to some of their pomological and phytonutrient characteristics. Molecules 2009, 14, 1808-1817. [CrossRef] [PubMed]

58. Solís, C.; Becerra, J.; Flores, C.; Robledo, J.; Silva, M. Antibacterial and antifungal terpenes from Pilgerodendron uviferum (D. Don) Florin. J. Chil. Chem. Soc. 2004, 49, 157-161. [CrossRef]

59. Randhir, R.; Lin, Y.T.; Shetty, K. Stimulation of phenolics, antioxidant and antimicrobial activities in dark germinated mung bean sprouts in response to peptide and phytochemical elicitors. Process Biochem. 2004, 39, 637-646. [CrossRef]

60. Castro, H.D.; Ferreira, F.A.; Silva, D.D.; Mosquim, P.R. Contribuição ao Estudo das Plantas Medicinais: Metabólitos Secundários, 2nd ed.; Biblioteca Nacional de Agricultura-BINAGRI Visconde do Rio Branco: Visconde do Rio Branco, Brasil, 2001.

(C) 2019 by the authors. Licensee MDPI, Basel, Switzerland. This article is an open access article distributed under the terms and conditions of the Creative Commons Attribution (CC BY) license (http://creativecommons.org/licenses/by/4.0/). 